Proceedings of the

International Geometry Center

Vol. 14, no. 1 (2021) pp. 49-60

\title{
Special semi-reducible pseudo-Riemannian spaces
}

\author{
Fedchenko Yu., Lesechko O.
}

\begin{abstract}
The paper contains necessary conditions allowing to reduce matrix tensors of pseudo-Riemannian spaces to special forms called semireducible, under assumption that the tensor defining tensor characteristic of semireducibility spaces, is idempotent. The tensor characteristic is reduced to the spaces of constant curvature, Ricci-symmetric spaces and conformally flat pseudo-Riemannian spaces.

The obtained results can be applied for construction of examples of spaces belonging to special types of pseudo-Riemannian spaces.

The research is carried out locally in tensor shape, without limitations imposed on a sign of a metric.
\end{abstract}

Анотація. В роботі досліджується можливість зведення метричного тензора псевдоріманових просторів до спеціального виду, який називають напівзвідністю. Тензорна ознака спрощується для просторів сталої кривини, Річчі-симетричних просторів та конформно-плоских псевдоріманових просторів. Отримані умови носять необхідний характер і базуються на ідемпотентності тензора, що задає тензорну ознаку напівзвідності простору. В роботі також вивчаються деякі властивості напівзвідних псевдоріманових просторів.

Для напівзведення метрики псевдоріманового простору необхідно і достатньо виконання умов алгебраїчного та диференціального характеру. Ці умови називаються тензорною ознакою напівзвідності. Досліджуються умови диференціювання та їх продовження для тензорної ознаки. Зокрема, доведено, що вектор із тензорної ознаки напівзвідності лежить в ядрі тензора з цієї ж ознаки.

UDC 514.765.1+512.813.4

Keywords: pseudo-Riemannian spaces, semi-reducible spaces, special pseudoRiemannian spaces.

Ключові слова: псевдо-ріманові простори, напівзвідні простори, спеціальні псевдоріманові простори.

DOI: http://dx.doi.org/10.15673/tmgc.v14i1.1940 
Для спеціальних просторів, просторів сталої кривини, Річчі-симетричних просторів та конформно-плоских просторів знайдені умови, яким задовольняють ці вектор та тензор за необхідністю. При отриманні результатів використовувалась властивість ідемпотентності тензора з ознаки напівзвідності. Умова ідемпотентності важлива для напівзведення просторів без вимоги знаковизначення метричного тензора.

Тому отримані результати цікаві для вивчення просторів з умовою ідемпотентності. Як відомо, умова ідемпотентності може бути послаблена і замінена вимогою, щоб матриця тензора $b_{i j}$ мала прості елементарні дільники та дійсні корені. В такому вигляді умова наводиться в книзі Л. Ейзенхарта «Ріманова геометрія», але без вимоги існування дійсних коренів.

Актуальним залишається питання вивчення достатніх умов, а також умов глобального чи топологічного характеру. Це дозволить ефективно досліджувати геометричні властивості, як узагальнених просторів, так і конкретних просторів загальної теорії відносності.

Результати можуть бути застосовані при побудові прикладів просторів, що належать до спеціальних типів псевдоріманових просторів.

Дослідження ведуться локально, в тензорній формі, без обмежень на знак метрики.

\section{INTRODUCTION}

Semi-reducible decomposition of the metric of a pseudo-Riemannian space $V_{n},(n>2)$, with a metric tensor $g_{i j}$ is a representation of the following form

$$
d s^{2}=d s_{1}^{2}\left(x^{1}, x^{2}, \ldots, x^{r}\right)+\sigma\left(x^{1}, x^{2}, \ldots, x^{r}\right) d s_{2}^{2}\left(x^{r+1}, x^{r+2}, \ldots, x^{n}\right) .
$$

Here $d s_{1}^{2}$ and $d s_{2}^{2}$ are independent metrics defined in different coordinates and the function $\sigma$ depends on the coordinates $d s_{1}^{2}$ only.

A space $V_{n}$ that permits at least one semi-reducible decomposition is called a semi-reducible space.

The following extreme cases of decomposition are paid a special attention

$$
d s^{2}=\left(d x^{1}\right)^{2}+\rho\left(x_{1}\right) d s_{1}^{2}\left(x^{2}, x^{3}, \ldots, x^{n}\right)
$$

and

$$
d s^{2}=d s_{1}^{2}\left(x^{1}, x^{2}, \ldots, x^{n-1}\right)+\rho\left(x^{1}, x^{2}, \ldots, x^{n-1}\right)\left(d x^{n}\right)^{2} .
$$

Pseudo-Riemannian spaces, where the equation (1.1) holds, are called equidistant. Equation (1.1) is a necessary and sufficient condition for existence of concircular vector field in $V_{n}[1,10]$.

Condition (1.2) can be treated as a generalization of the static metric in general theory of relativity. 


\section{Tensor CHARACTERISTiC OF SEMI-REDUCIBLE SPACES}

A pseudo-Riemannian space $V_{n}$ can be represented as a semi-reducible space if and only if there exists a symmetrical idempotent tensor which is not proportional to metric in this space.

The latter tensor should correspond to the following limitation

$$
\begin{aligned}
b_{\alpha i} b_{j}^{\alpha} & =b_{i j}, \\
b_{i j, k} & =u_{i} b_{j k}+u_{j} b_{i k} .
\end{aligned}
$$

Here $u_{i}=u_{, i}=\partial_{i} u$ are some gradient vector, comma is a sign of a covariant derivative, and $b_{j}^{i}=b_{\alpha j} g^{\alpha i}, g^{i j}$ are elements of the inverse matrix to $g_{i j}$.

Equations (2.1) and (2.2) are called tensor characteristic of semi-reducibility of pseudo-Riemannian spaces. This paper treats semi-reducible spaces, which differ from reducible spaces, namely by the fact that $u_{i} \neq 0$.

Tensor characteristic of semi-reducible spaces was found by G. I. Kruchkovich $[10,11]$.

Diferentiating (2.1) and taking into account (2.2), we can get

$$
u_{\alpha} b_{j}^{\alpha} b_{i k}+u_{\alpha} b_{i}^{\alpha} b_{j k}=0
$$

Alternating by indices $j, k$ also gives

$$
u_{\alpha} b_{j}^{\alpha} b_{i k}-u_{\alpha} b_{k}^{\alpha} b_{i j}=0 .
$$

Let us re-assign indices $i$ and $k$

$$
u_{\alpha} b_{j}^{\alpha} b_{k i}-u_{\alpha} b_{i}^{\alpha} b_{k j}=0 \text {. }
$$

Then adding (2.4) and (2.3) up, we can clearly see, that

$$
u_{\alpha} b_{j}^{\alpha}=0
$$

which implies

where $u^{i}=u_{\alpha} g^{\alpha i}$.

$$
u_{\alpha, i} b_{j}^{\alpha}=-u_{\alpha} u^{\alpha} b_{i j}
$$

Taking into account the Ricci identity, integrability conditions for (2.2) can be written down as follows:

$$
\begin{aligned}
b_{\alpha i} R_{j k l}^{\alpha}+ & b_{\alpha j} R_{i k l}^{\alpha}=\left(u_{l, i}-u_{l} u_{i}\right) b_{j k}+ \\
& +\left(u_{l, j}-u_{l} u_{j}\right) b_{i k}-\left(u_{k, i}-u_{k} u_{i}\right) b_{j l}-\left(u_{k, j}-u_{k} u_{j}\right) b_{i l} .
\end{aligned}
$$

Here $R_{i j k}^{h}$ is a Riemann tensor for $V_{n}$.

Wrapping (2.7) and substituting (2.5) and (2.6), we move to the expression

$$
\left(u_{l, i}-u_{l} u_{i}\right) b=\left(u_{\alpha,}^{\alpha}-u_{\alpha} u^{\alpha}\right) b_{i l}+b_{\alpha i} R_{l}^{\alpha}-b_{\alpha \beta} R_{. i l .}^{\alpha \beta},
$$

where $b=b_{\alpha \beta} g^{\alpha \beta}, u_{\alpha,}^{\alpha}=u_{\alpha, \beta} g^{\alpha \beta}, R_{i l}^{h j}=R_{i l \beta}^{h} g^{\alpha j}[1,8]$.

Thus, we have proved the following statement 
Theorem 2.1. Vector $u_{i}$ in the tensor characteristic of semi-reducible pseudo-Riemannian spaces conforms to the conditions: (2.5), (2.6), (2.8).

Furthermore, wrapping (2.2) by indices $i, j$ and taking into account (2.5), we get

$$
b_{, i}=0 \text {. }
$$

Multiplying (2.8) by $b_{j}^{i}$ and wrapping by $i$, taking into account $(2.1)$, we obtain

$$
u_{\alpha,}^{\alpha} b_{i j}+b_{\alpha i} R_{j}^{\alpha}-b_{\alpha \beta} b_{i}^{\gamma} R_{\gamma j}^{\alpha \beta}=0 .
$$

Applying the obtained results we can formulate some expressions, which will be useful in the further discussion.

Let us wrap (2.8) with $u_{i}$ and $u_{l}$. Then we obtain respectively

$$
\begin{aligned}
& u^{\beta} b_{\alpha j} R_{\beta k l}^{\alpha}=u^{\alpha}\left(u_{l, \alpha}-u_{\alpha} u_{l}\right) b_{j k}-u^{\alpha}\left(u_{k, \alpha}-u_{\alpha} u_{k}\right) b_{j l} ; \\
& \quad b_{\alpha i} R_{j k \beta}^{\alpha} u^{\beta}+b_{\alpha j} R_{i k \beta}^{\alpha} u^{\beta}= \\
& \quad=u^{\alpha}\left(u_{\alpha, i}-u_{\alpha} u_{i}\right) b_{j k}+u^{\alpha}\left(u_{\alpha, j}-u_{\alpha} u_{j}\right) b_{i k} .
\end{aligned}
$$

Let us turn our attention to the direct research on semi-reducibility of special spaces.

\section{Semi-Reducible spaces of COnstant CuRvature}

Pseudo-Riemannian spaces $V_{n}$ are called spaces of constant curvature, when the Riemann tensor $V_{n}$ complies to the condition

$$
R_{i j k}^{h}=\frac{R}{n(n-1)}\left(\delta_{k}^{h} g_{i j}-\delta_{j}^{h} g_{i k}\right),
$$

here $\delta_{k}^{h}$ are Kronecker symbols, and $R$ is a scalar curvature of

$$
R=R_{\alpha \beta} g^{\alpha \beta}
$$

see $[14,15]$.

Substitute (3.1) in the integrability conditions of the tensor characteristic of semi-reducible spaces. Then, the following expression arises:

$$
\tau_{l i} b_{j k}+\tau_{l j} b_{i k}-\tau_{k i} b_{j l}-\tau_{k j} b_{i l}=0 .
$$

Here

$$
\tau_{i j}=u_{i, j}-u_{i} u_{j}+\frac{R}{n(n-1)} g_{i j} .
$$

Let us alternate (3.2) by indices $i, k$ :

$$
\tau_{l i} b_{j k}-\tau_{l k} b_{j i}-\tau_{k j} b_{i l}+\tau_{i j} b_{k l}=0,
$$

then re-assign indices $k$ and $j$ :

$$
\tau_{l i} b_{j k}-\tau_{l j} b_{k i}-\tau_{k j} b_{i l}+\tau_{i k} b_{j l}=0,
$$


and add (3.4) and (3.2):

$$
\tau_{l i} b_{j k}-\tau_{j k} b_{i l}=0 .
$$

Let us also wrap the latter with $g^{j k}$ :

$$
b \tau_{l i}=\tau b_{l i}
$$

where $\tau=\tau_{\alpha \beta} g^{\alpha \beta}$.

Taking into account (3.3) we get

$$
b\left(u_{i, j}-u_{i} u_{j}+\frac{R}{n(n-1)} g_{i j}\right)=\tau b_{i j} .
$$

Let us calculate the covariant derivative of the expression (3.5):

$$
b\left(u_{i, j k}-u_{i, k} u_{j}-u_{i} u_{j, k}\right)=\tau_{, k} b_{i j}+\tau u_{i} b_{j k}+\tau u_{j} b_{i k} .
$$

Taking into account (3.5) in the equation (3.6):

$$
\begin{aligned}
& b u_{i, j k}-\tau b_{i k} u_{j}-\tau b_{j k} u_{i}-2 b u_{i} u_{k} u_{j}+ \\
& +\frac{R b}{n(n-1)} u_{j} g_{i j}+\frac{R b}{n(n-1)} u_{i} g_{i j}= \\
& \quad=\tau_{, k} b_{i j}+\tau u_{i} b_{j k}+\tau u_{j} b_{i k} .
\end{aligned}
$$

Let us alternate by indices $j, k$

$$
b u_{\alpha} R_{i j k}^{\alpha}=\frac{R b}{n(n-1)}\left(u_{k} g_{i j}-u_{j} g_{i k}\right)+b_{i j}\left(\tau_{, k}-2 \tau u_{k}\right)-b_{i k}\left(\tau_{, j}-2 \tau u_{j}\right),
$$

and substitute (3.1) into the latter formula:

$$
b_{i j}\left(\tau_{, k}-2 \tau u_{k}\right)-b_{i k}\left(\tau_{, j}-2 \tau u_{j}\right)=0 .
$$

Multiplying (3.5) by $b_{k}^{i}$ and wrapping by index $i$, we get

$$
b\left(\frac{R}{n(n-1)}-u_{\alpha} u^{\alpha}\right)=\tau,
$$

which implies

$$
\tau_{, i}=-2 b u^{\alpha} u_{\alpha, i}
$$

Hence (3.7) reduces to the following form:

$$
\rho_{k} b_{i j}-\rho_{j} b_{i k}=0
$$

where

Let us wrap (3.8) with $g^{i j}$ :

$$
\rho_{k}=b u^{\alpha} u_{\alpha, k}+\tau u_{k}
$$

$$
b \rho_{k}=\rho_{\alpha} b_{k}^{\alpha}
$$

Now using the latter identity, let us also wrap (3.8) with $b_{m}^{k}$ and re-assign indices $k$ and $m$ :

$$
b \rho_{k} b_{i j}-\rho_{j} b_{i k}=0
$$


By subtracting (3.8) and(3.9), we get $b=1$ or $\rho_{k}=0$.

Suppose that $\rho_{k} \neq 0$. Then we can choose a vector $\xi^{k}$ in such a way that: $\rho_{\alpha} \xi^{\alpha}=1$ and taking into account (3.8) we get

$$
b_{i j}=\gamma \rho_{i} \rho_{j}
$$

where $\gamma$ is some invariant, $\gamma \rho_{\alpha} \rho^{\alpha}=1[4,5]$.

Theorem 3.1. Conditions (3.10) or $b u^{\alpha} u_{\alpha, k}+\tau u_{k}=0$ hold in semireducible spaces of constant curvature.

\section{Semi-Reducible RicCi-Symmetric SPaCeS}

Pseudo-Riemannian spaces $V_{n}$ are called Ricci-symmetric, whenever the the Ricci tensor of $V_{n}$ satisfies the following identity [6, 9]:

$$
R_{i j, k}=0 \text {. }
$$

Symmetrizing the equation (2.8) we get:

$$
b_{\alpha i} R_{j}^{\alpha}-b_{\alpha j} R_{i}^{\alpha}=0 .
$$

The latter, together with (2.2), implies

$$
u_{\alpha} R_{j}^{\alpha} b_{i k}+u_{i} b_{\alpha k} R_{j}^{\alpha}+b_{\alpha i} R_{j, k}^{\alpha}-u_{\alpha} R_{i}^{\alpha} b_{j k}-u_{j} b_{\alpha k} R_{i}^{\alpha}-b_{\alpha j} R_{i, k}^{\alpha}=0 .
$$

Multiplying (4.2) by $u^{j}$ and wrapping by index $j$, we obtian

$$
b_{\alpha i} R_{\beta}^{\alpha} u^{\beta}=0 \text {. }
$$

Equaton (4.3), when (4.1) and (4.2) are taking into consideration, can be re-written as follows:

$$
u_{\alpha} R_{j}^{\alpha} b_{i k}+u_{i} b_{\alpha k} R_{j}^{\alpha}-u_{\alpha} R_{i}^{\alpha} b_{j k}-u_{j} b_{\alpha i} R_{k}^{\alpha}=0 .
$$

Multiplying (4.4) by $b_{m}^{i}$, and wrapping it by index $i$ and re-assigning $i$ and $m$ we obtain:

$$
u_{\alpha} R_{j}^{\alpha} b_{i k}-u_{j} b_{\alpha i} R_{k}^{\alpha}=0 .
$$

As far as $b_{i j} \neq 0$ and $u_{i} \neq 0,(4.5)$ implies

$$
u_{\alpha} R_{i}^{\alpha}=\stackrel{1}{\tau} u_{i}
$$

and

$$
b_{\alpha i} R_{j}^{\alpha}=\stackrel{2}{\tau} b_{i j}
$$

Here $\stackrel{1}{\tau}, \underset{\tau}{\tau}$ are some invariants.

Differentiating (4.7), we get

$$
\stackrel{1}{\tau} u_{j} b_{i k}=\stackrel{2}{\tau}{ }_{k} b_{i j}+\stackrel{2}{\tau} u_{j} b_{i k}
$$


Multiplying (4.8) by $b_{m}^{j}$, wrapping by $j$ we can see that $\stackrel{2}{\tau}_{k}=0$. Then equation (4.8) transforms into the following identity:

$$
(\stackrel{1}{\tau}-\stackrel{2}{\tau}) u_{j} b_{i k}=0
$$

whence $\stackrel{1}{\tau}=\stackrel{2}{\tau}=$ const. Thus, the following statement is true

Theorem 4.1. Conditions (4.6), (4.7) hold in semi-reducible Ricci-symmetric spaces, while $\stackrel{1}{\tau}=\stackrel{2}{\tau}$ are constant.

Corollary 4.2. Vector $u_{i}$ complies to the following conditions in the semireducible Ricci-symmetric spaces

$$
b\left(u_{i, j}-u_{i} u_{j}\right)=\left(u_{, \alpha}^{\alpha}-u_{\alpha} u^{\alpha}+\frac{1}{\tau}\right) b_{i j}-b_{\alpha \beta} R_{i j}^{\alpha}{ }^{\beta}
$$

It is easy to see that (4.9) is true, if we substitute (4.7) in (2.8).

The Ricci identity for the vector $u_{i}$ implies:

$$
u_{i, j k}-u_{i, k j}=u_{\alpha} R_{i j k}^{\alpha} .
$$

We can prove the following corollary.

Corollary 4.3. Vector $u_{i}$ complies to the following conditions in semireducible Ricci-symmetric spaces

$$
u_{, \alpha k}^{\alpha}-u_{, k \alpha}^{\alpha}=\stackrel{1}{\tau} u_{i} .
$$

Spaces whose Ricci tensor satisfies the following conditions

$$
R_{i j}=\frac{R}{n} g_{i j}
$$

are called Einstein spaces $[7,9]$.

For Einstein spaces the scalar curvature $R$ is always constant. Einstein spaces are particular cases of Ricci-symmetric spaces. Therfefore the following statement hold:

Corollary 4.4. In semi-reducible Einstein spaces $\stackrel{1}{\tau}=\frac{R}{n}$.

\section{SEMI-REDUCIBLE CONFORMAL FLAT SPACES}

A necessary and sufficient condition for a pseudo-Riemannian space to be defined as a conformal flat space is his compliance to the following conditions $[3,13]$

$$
\begin{gathered}
R_{h i j k}=P_{h k} g_{i j}-P_{h j} g_{i k}+P_{i j} g_{h k}-P_{i k} g_{h j}, \\
P_{i j, k}-P_{i k, j}=0
\end{gathered}
$$


where

$$
P_{i j}=\frac{1}{n-2}\left(R_{i j}-\frac{1}{2(n-1)} R g_{i j}\right) .
$$

Taking into account (5.3) we can write (4.2) in the following form

$$
b_{\alpha i} P_{j}^{\alpha}-b_{\alpha j} P_{i}^{\alpha}=0 \text {, }
$$

where $P_{i}^{h}=P_{\alpha i} g^{\alpha h}$.

Substituting (5.1) in (2.7), we get

$$
\begin{aligned}
b_{\alpha i} P_{l}^{\alpha} g_{j k}-b_{\alpha i} P_{k}^{\alpha} g_{j l}+ & b_{\alpha j} P_{l}^{\alpha} g_{i k}-b_{\alpha j} P_{k}^{\alpha} g_{i l}= \\
& =b_{j k} \lambda_{l i}+b_{i k} \lambda_{l j}-b_{l i} \lambda_{j k}-b_{l j} \lambda_{i k},
\end{aligned}
$$

where

$$
\lambda_{i j}=u_{i, j}-u_{i} u_{j}+P_{i j} .
$$

Alternating (5.4) by indices $j$ and $l$

$$
\begin{aligned}
b_{\alpha i} P_{l}^{\alpha} g_{j k}-b_{\alpha i} P_{j}^{\alpha} g_{l k}- & b_{\alpha j} P_{k}^{\alpha} g_{i l}+b_{\alpha l} P_{k}^{\alpha} g_{i j}= \\
& =b_{j k} \lambda_{l i}-b_{l k} \lambda_{j i}-b_{l i} \lambda_{j k}+b_{j i} \lambda_{l k}
\end{aligned}
$$

and re-assigning indices $i$ and $l$ we obtain:

$$
\begin{aligned}
b_{\alpha l} P_{i}^{\alpha} g_{j k}-b_{\alpha l} P_{j}^{\alpha} g_{i k}- & b_{\alpha j} P_{k}^{\alpha} g_{l i}+b_{\alpha i} P_{k}^{\alpha} g_{l i}= \\
& =b_{j k} \lambda_{i l}-b_{i k} \lambda_{j l}-b_{i l} \lambda_{j k}+b_{j l} \lambda_{i k} .
\end{aligned}
$$

Summing up (5.6) and (5.4), we pass to

$$
b_{\alpha i} P_{l}^{\alpha} g_{j k}-b_{\alpha j} P_{k}^{\alpha} g_{i l}=b_{j k} \lambda_{l i}-b_{i l} \lambda_{j k} .
$$

Further, wrap the latter equation by $j, k$ :

$$
b_{\alpha i} P_{l}^{\alpha}=\frac{b}{n} \lambda_{l i}-\frac{\lambda}{n} b_{i l}+\frac{\check{P}}{n} g_{i l},
$$

where $\check{P}=b_{\beta}^{\alpha} P_{\alpha}^{\beta}$.

Multiplying (5.8) by vector $u^{i}$ and wrapping it by index $i$ we get:

$$
b u^{\alpha} \lambda_{\alpha l}+\check{P} u_{l}=0 .
$$

Multiplying (5.7) by $b u^{j}$ and wrapping it by index $j$, taking into account (5.9), we obtaiin

$$
b b_{\alpha i} P_{l}^{\alpha} u_{k}=\check{P} u_{k} b_{i l},
$$

which can also be written as follows:

$$
b b_{\alpha i} P_{l}^{\alpha}=\check{P} b_{i l} .
$$

Hence one can write (5.8) in the following form:

$$
b^{2} \lambda_{j i}-(b \lambda+n \check{P}) b_{i j}+b \check{P} g_{i j}=0 \text {. }
$$


Substituting (5.5) into the latter identity we get

$$
b^{2}\left(u_{i, j}-u_{i} u_{j}\right)+b^{2} P_{i j}+b \check{P} g_{i j}-(b \lambda+n \check{P}) b_{i j}=0 \text {. }
$$

Now multiply (5.10) by $b_{k}^{i}$ and wrap by index $i$

$$
\left(-b^{2} u^{\alpha} u_{\alpha}+2 P \check{P}-b \lambda-n \check{P}\right) b_{j k}=0 .
$$

Hence

$$
\check{P}=\frac{b\left((b-1) u^{\alpha} u_{\alpha}+u_{, \alpha}^{\alpha}+P\right)}{2 b-n} .
$$

Therefore (5.10) can be written as follows

$$
u_{i, j}-u_{i} u_{j}+P_{i j}+\mu g_{i j}-\stackrel{3}{\tau} b_{i j}=0
$$

where $\mu=\frac{\check{P}}{b}$ and $\stackrel{3}{\tau}=-(b \lambda+n \check{P}) \frac{1}{b^{2}}$.

Differentiating (5.11), we get

$$
u_{i, j k}-u_{i, k} u_{j}-u_{i} u_{j, k}+P_{i j, k}+\mu_{k} g_{i j}++\stackrel{3}{\tau} b_{k j}+\stackrel{3}{\tau} b_{i k} u_{j}+\stackrel{3}{\tau} b_{j k} u_{i}=0,
$$

where $\mu_{k}=\mu_{, k}=\partial_{k} \mu ; \stackrel{3}{\tau}_{k}=\stackrel{3}{\tau}, k=\partial_{k} \stackrel{3}{\tau}$.

Alternating (5.12) and taking into account the Ricci identity, we obtain

$$
\begin{aligned}
u_{\alpha} R_{i j k}^{\alpha}-u_{i, k} u_{j}+u_{i, j} u_{k}+\mu_{k} g_{i j} & -\mu_{j} g_{i k}+ \\
& +\left(\stackrel{3}{\tau}_{k}-\stackrel{3}{\tau} u_{k}\right) b_{i j}-\left(\stackrel{3}{\tau}_{j}-\stackrel{3}{\tau} u_{j}\right) b_{i k}=0 .
\end{aligned}
$$

Taking into account(5.11) and (5.1)

$$
\begin{aligned}
&\left(u_{\alpha} P_{k}^{\alpha}-\mu u_{k}+\mu_{k}\right) g_{i j}-\left(u_{\alpha} P_{j}^{\alpha}-\mu u_{j}+\mu_{j}\right) g_{i k}+ \\
&+\left(\stackrel{3}{\tau}_{k}-2 \stackrel{3}{\tau} u_{k}\right) b_{i j}-\left(\stackrel{3}{\tau}_{j}-2 \stackrel{3}{\tau} u_{j}\right) b_{i k}=0 .
\end{aligned}
$$

Multiply (5.13) by vector $u^{i}$, and wrap by index $i$ :

$$
\left(u_{\alpha} P_{k}^{\alpha}-\mu u_{k}+\mu_{k}\right) u_{j}-\left(u_{\alpha} P_{j}^{\alpha}-\mu u_{j}+\mu_{j}\right) u_{k}=0 .
$$

Asssuming that $u_{i} \not \equiv 0$, choose a vector $\xi^{i}$ so that $\xi^{\alpha} u_{\alpha}=1$. Then

$$
u_{\alpha} P_{k}^{\alpha}-\mu u_{k}+\mu_{k}=\stackrel{4}{\tau} u_{k}
$$

where $\stackrel{4}{\tau}=\left(u_{\alpha} P_{\beta}^{\alpha}-\mu u_{\beta}+\mu_{\beta}\right) \xi^{\beta}$.

Substituting (5.14) into (5.13), we get

$$
\stackrel{4}{\tau} u_{k} g_{i j}-\stackrel{4}{\tau} u_{j} g_{i k}+\left(\stackrel{3}{\tau}_{k}-2 \stackrel{3}{\tau} u_{k}\right) b_{i j}-\left(\stackrel{3}{\tau_{j}}-2 \stackrel{3}{\tau} u_{j}\right) b_{i k}=0
$$

Multiplying by $b_{l}^{k}$, wrapping by index $k$ and re-assigning $l$ by $k$ :

$$
b_{k}^{\alpha} \stackrel{3}{\tau}_{\alpha} b_{i j}-\left(\stackrel{3}{\tau}_{j}-2 \stackrel{3}{\tau} u_{j}+\stackrel{4}{\tau} u_{j}\right) b_{i k}=0 .
$$


Wrapping (5.16) by indices $i$ and $k$, we obtain

$$
b_{j}^{\alpha} \stackrel{3}{\tau}_{\alpha}-b\left(\stackrel{3}{\tau}_{j}-2 \stackrel{3}{\tau} u_{j}+\stackrel{4}{\tau} u_{j}\right)=0
$$

Wrapping further (5.16) by indices $i$ and $j$, we also obtain

$$
b b_{k}^{\alpha} \stackrel{3}{\tau}_{\alpha}-\stackrel{3}{\tau}_{\alpha} b_{k}^{\alpha}=0
$$

Then (5.18) and (5.17) imply that $b=1$ and equations (5.17) can be written as follows:

$$
b_{j}^{\alpha} \stackrel{3}{\tau}_{\alpha}=\stackrel{3}{\tau}_{j}-2 \stackrel{3}{\tau} u_{j}+\stackrel{4}{\tau} u_{j}
$$

Hence (5.16) takes the following form:

$$
b_{k}^{\alpha} \stackrel{3}{\tau}_{\alpha} b_{i j}=b_{j}^{\alpha} \stackrel{3}{\tau}_{\alpha} b_{i k}
$$

Wrapping (5.15) by indices $i$ and $j$, taking into account (5.19), we see that

$$
\stackrel{4}{\tau}=0
$$

Equations (5.14) can be transformed into the following form:

$$
u_{\alpha} P_{k}^{\alpha}=\mu u_{k}-\mu_{k}
$$

Furthermore, equation (5.15) means that

$$
\stackrel{3}{\tau}_{i}=2 u_{i} \stackrel{3}{\tau}
$$

Theorem 5.1. If a conformal flat space permits a semi-reducible decomposition, then vector $u_{i}$ complies to equations (5.11), invariant $\mu$ (5.20), and $\stackrel{3}{\tau}$ is defined by formula $\stackrel{3}{\tau}=e^{2 u}$.

Thus, we have found the conditions of differential nature, which constraint the vector $u_{i}$ and parameters of obtained differential equation [12, $16,17]$.

\section{Conclusion}

The paper treats some characteristics of semi-reducible pseudo-Riemannian spaces. Certain algebraic and differential conditions are necessary and sufficient in order to define the metric of pseudo-Riemannian spaces as semi-reducible. These conditions are called a tensor characteristic of semireducibility. We study conditions of differentiating and their extensions for a tensor characteristic.

Namely, we proved that the vector of tensor characteristic of semi-reducibility lies in the core of the tensor of this characteristic. For some categories of specialized spaces (spaces of constant curvature, Ricci-symmetric spaces and conformal flat spaces) we found conditions, which limit these vector and tensor with a necessity. In order to get these results we applied 
a property of idempotence of a tensor of semi-reducibility characteristic. The condition of idempotence is important for semi-reducibility of spaces without limitations imposed on a sign of metric tensor.

Thus, the obtained results are interesting for the research on spaces with condition of idempotence. As it is known [18], the condition of idempotence can be weakened and replaces with the condition, that the matrix of tensor $b_{i j}$ should have simple elementary divisors and real roots. At least, in such a way, this condition is cited in the L. Eisenhart's book "Riemannian geometry" [2], but there is no part of the condition on real roots.

The particular attention is deserved by the research on positive conditions and conditions of global or topological type [18]. It will facilitate an effective research on geometric properties both generalized spaces and definite spaces of general theory of relativity.

\section{REFERENCES}

[1] D. Doikov, V. Kiosak. On the schwarzschild model for gravitating objects of the Universe. AIP Conference Proceedings, 2302(040001), 2020, doi: 10.1063/5.0033657.

[2] L.P. Eisenhart. Riemannian geometry. Princeton University Press, 1997.

[3] I. Hinterleitner, V. Kiosak. $\varphi$ (ric)-vector fields on conformally flat spaces. Proceedings of American Institute of Physics, 1191:98-103, 2009, doi: 10.1063/1.3275604.

[4] V. Kiosak, A. Savchenko, O. Gudyreva. On the conformal mappings of special quasi-Einstein spaces. AIP Conference Procedings, 2164(040001), 2019, doi: $10.1063 / 1.5130793$.

[5] V. Kiosak, A. Savchenko, A. Kamienieva. Geodesic mappings of compact quasi-Einstein spaces with constant scalar curvature. AIP Conference Procedings, 2302(040002), 2020, doi: $10.1063 / 5.0033661$.

[6] V. Kiosak, A. Savchenko, S. Khniunin. On the typology of quasi-Einstein spaces. AIP Conference Procedings, 2302(040003), 2020, doi: 10.1063/5.0033700.

[7] V. Kiosak, A. Savchenko, G. Kovalova. Geodesic mappings of compact quasi-Einstein spaces, I. Proc. Int. Geom. Cent., 13(1):35-48, 2020, doi: 10.15673/tmgc.v13i1.1711.

[8] V.A. Kiosak, G.V. Kovalova. Geodesic mappings of quasi-Einstein spaces with a constant scalar curvature. Matematychni Studii, 53(2):212-217, 2020, doi: $10.30970 /$ ms.53.2.212-217.

[9] D. Kramer, H. Stephani, M. Maccollum, E. Herlt. Exact solutions of the Einstein field equations. Leutscher Verlag der Wissenschaften, Berlin, 1980, doi: $10.1017 /$ cbo9780511535185.

[10] G.I. Kruchkovich. Geodesic correspondence of semi-reducible Riemannian spaces. Dokl. Akad. Nauk SSSR, 152(1):43-45, 1963.

[11] G.I. Kruchkovich. Riemannian and pseudo-Riemannian spaces. Itogi Nauki. Ser. Mat. Algebra. Topol. Geom., pages 191-220, 1968.

[12] O. Lesechko, O. Latysh, A. Kamienieva. Models of mechanical systems preserving the Weyl tensor. AIP Conference Proceedings, 2164(040002), 2019, doi: 10.1063/1.5130794.

[13] O. Lesechko, O. Latysh, T. Spychak. Conformally flat Kähler spaces. AIP Conference Proceedings, 2302(040004), 2020, doi: 10.1063/5.0034024.

[14] J. Mikeš, V.A. Kiosak, O. Vanžurova. Geodesic mappings of manifolds with affine connection. Palacky̌ University Press, Olomouc, 2008. 
[15] T. Shevchenko, O. Gudyreva, Ju. Fedchenko. Conformal mappings preserving the curvature of multi-dimensional platforms. AIP Conference Proceedings, 2302(040009), 2020, doi: $10.1063 / 5.0033941$.

[16] Y. Vashpanov, O. Olshevska, O. Lesechko. Geodesic mappings of spaces with $\varphi$ (ric) vector fields. AIP Conference Proceedings, 2302(040010), 2020, doi: 10.1063/5.0033965.

[17] N. Vashpanova, T. Podousova, Ju. Fedchenko. Canonical deformations of pseudo-Riemannian spaces. AIP Conference Proceedings, 2164(040005), 2019, doi: $10.1063 / 1.5130797$.

[18] M. Zarichnyi, A. Savchenko, V. Kiosak. Strong topology on the set of persistence diagrams. AIP Conference Procedings, 2164(040006), 2019, doi: 10.1063/1.5130798.

Received: January 31, 2021, accepted: March 20, 2021.

Fedchenko Yu.

Odesa National Academy of Food Technologies, Kanatna st., 112, 65039 Odesa, UKRAINE

Email: fedchenko20@ukr.net

ORCID: orcid.org/0000-0002-7473-3237

Lesechko O.

Odesa State Academy of Civil Engineering and Architecture, Didrihson st., 4, 65029 OdESA, UKRAINE

Email: a.lesechko@ukr.net

ORCID: orcid.org/0000-0002-2352-6174 